\title{
Effect of neonatal undernutrition on serum follicle-stimulating hormone levels and ovarian development in the female rat
}

\author{
BY P. E. SCHENCK, A. KOOS SLOB, J. TH. J. UILENBROEK AND \\ J. J. VAN DER WERFF TEN BOSCH \\ Department of Endocrinology, Growth and Reproduction, Faculty of Medicine, \\ Erasmus University, Rotterdam, The Netherlands
}

(Received 23 January $1980-$ Accepted I0 March 1980)

\begin{abstract}
I. Female rats were undernourished from birth through replacement for $12 \mathrm{~h} / \mathrm{d}$ of the lactating mother by a nipple-ligated mother. This resulted in slow growth so that at $22 \mathrm{~d}$ of age the body-weights equalled those of well-nourished animals at $14 \mathrm{~d}$.

2. At 14, 17, 20 and $22 \mathrm{~d}$ groups of eight to ten animals each of undernourished and well-nourished rats were autopsied, serum follicle-stimulating hormone (FSH) concentration was determined by radioimmunoassay, uteruses were weighed and ovaries examined by light microscopy.

3. Undernutrition caused a 3-4 d delay in the third-week drop in serum FSH and in ovarian development as indicated by the numbers of antral follicles and by the maximal diameter of the ovaries and of the largest follicles.

4. It is postulated that the effect of undernutrition on serum FSH may be due to delayed increase in ovarian feedback effectiveness, which may be the result of either the retardation in ovarian development or a continued high level of serum oestrogen-binding protein. It remains uncertain through which mechanism(s) undernutrition brings about delayed onset of puberty.
\end{abstract}

Normal female rats have high serum follicle-stimulating hormone (FSH) levels at the age of I0-15 d (Kragt \& Dahlgren, 1972). The biological significance of this phenomenon is not clear. It seems possible that there is a causal relationship between the peak in serum FSH levels and the timing of the onset of puberty. Uilenbroek \& Arendsen de Wolff-Exalto (I979) have examined the effect of FSH suppression on pubertal signs in female rats. To this end $5^{\alpha}$-dihydrotestosterone propionate was administered on postnatal days $5,10,15$ and 20 in doses of 0.1 and $\mathrm{I} \cdot 0 \mathrm{mg} /$ injection. The low dose caused only partial suppression of serum FSH from day ro to day 30 and had no influence on the time of puberty as indicated by first ovulation and first occurrence of vaginal cornification. The high dose caused suppression of serum FSH to the low level that normally occurs in adult female rats, and was followed by a $4 \mathrm{~d}$ delay in first ovulation and vaginal oestrus. The delay in the onset of puberty may have been due, in this instance, to the absence of the peak in serum FSH. A different approach to examine the interrelationship between serum FSH and puberty is to alter experimentally the time of onset of puberty, and to study FSH levels; a delay of puberty might be accompanied by changes in the height or the timing of the FSH peak in serum or both in the second week of postnatal life. In the present study neonatal undernutrition, which is known to delay the onset of puberty (Kennedy \& Mitra, 1963), was used as a method for obtaining rats with a delayed onset of puberty.

\section{MATERIALS AND METHODS}

Rats were undernourished from birth until autopsy 2-3 weeks later. The young (Wistar Amsterdam $\mathbf{R}$ strain, bred in our own laboratory) of several litters born on the same day, were mixed and randomly re-assigned to groups of three mothers, eight pups per doe, at least four of which were females. One of each group of three mothers had her nipples 
ligated on the day of parturition to prevent the delivery of milk (Lynch, 1976). The animal room lights were on from $06.00-18.00$ hours. At 12.00 hours, the middle of the light period, the nipple-ligated mother was moved from litter no. I to litter no. 2 and the lactating mothers from litter no. 2 to litter no. 3 and from litter no. 3 to litter no. I. At 24.00 hours, the middle of the dark period, the mothers were moved back to their former litters. This procedure resulted in the undernourishment of litters nos. I and 2, because they had access to a lactating mother for only $12 \mathrm{~h} / \mathrm{d}$. The third litter was with a lactating mother for $24 \mathrm{~h} / \mathrm{d}$. On days $14,17,20$ and 22 the pups were weighed and one female animal was randomly selected from each litter for autopsy; in all, ten, ten, ten and eight undernourished animals and ten, ten, ten and eight well-nourished animals respectively were studied at these various ages. At autopsy blood was collected by decapitation ( 14 and $17 \mathrm{~d}$ of age) or, under light diethylether anaesthesia, from the ophthalmic venous plexus ( 20 and $22 \mathrm{~d}$ of age). Serum was frozen until FSH determination by radioimmunoassay (Welschen et al. 1975). The uterus was removed and weighed, the ovaries were prepared for histological examination. Every tenth $\mu \mathrm{m}$ thick section was mounted and stained with haematoxylin and eosin. Ovarian morphology was quantified in the following manner; the largest section was selected in order: (I) to count the number of follicles with more than two layers of granulosa cells, without visible antrum but with visible oocyte (preantral follicles); (2) to count the number of follicles with more than two layers of granulosa cells, with a visible antrum (antral follicles); (3) to measure the greatest ovarian diameter; (4) to record the greatest follicular diameter.

\section{RESULTS}

It can be seen in Fig. I that undernutrition caused a lag in body-weight growth of approximately $8 \mathrm{~d}$. There was a 3-4 d postponement of the fall of FSH in the third week of life and an equivalent retardation of ovarian development as indicated by the later occurrence of an equivalent number of antral follicles and ovarian and follicular diameters. Analysis of variance revealed significant over-all differences between control and undernourished animals in uterus weight $(P<0.01)$ and in number of follicles without an antrum $(P<0.05)$ and with an antrum $(P<0.01)$. These variables also changed significantly with age. For body-weight, FSH, ovarian diameter and largest follicular diameter there was a significant interaction between food regimen and age, the differences between controls and undernourished animals changing with age. More detailed analysis with the simple main-effect method (Kirk, 1968) showed that the difference in body-weight was significant at all ages, and that all differences in ovarian and follicular diameters and in FSH levels were significant from day 17 onwards.

\section{DISCUSSION}

In both groups of rats the decrease in FSH level was associated with a sharp rise in the number of antral follicles. These findings suggest that the third-week drop in FSH results from a negative feedback action exerted by the maturing ovarian follicles when they reach a critical stage of development. The delay in this FSH drop in undernourished rats may be due to the delay in ovarian follicular development; this could result in deficient secretion of ovarian feedback hormone(s). This view is not incompatible with the finding of sustained growth of the uterus, since Price (1947) found considerable uterine growth in rats spayed when $2 \mathrm{~d}$ of age. It is not clear how undernutrition leads to inhibition of ovarian development. Delayed gonadal maturation may be symptomatic of the retarded growth of all parts of the body, and be caused by deficiency of nutrients or deficiencies of pituitary hormones or both. Thus it is of interest that in growth hormone-deficient children puberty may be delayed and that treatment with growth hormone may accelerate the onset of puberty (Sheikholislam \& Stempfel, 1972). 
(a)

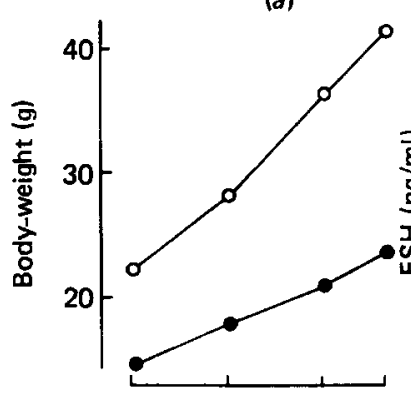

(d)

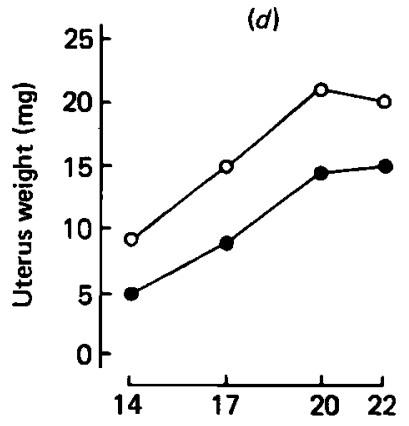

(b)
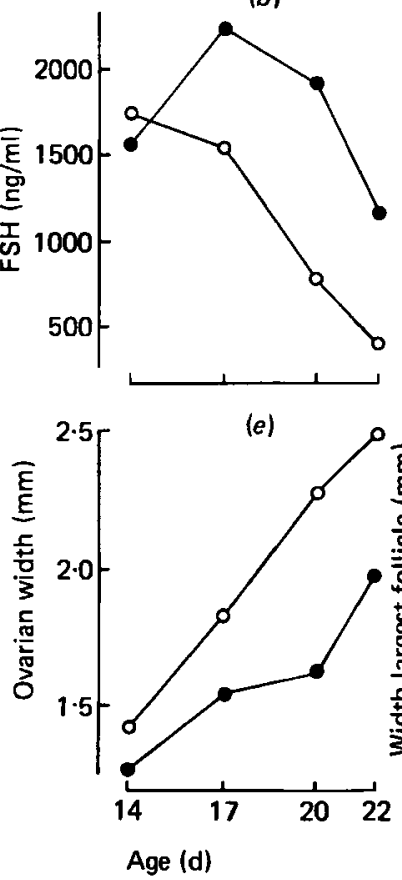

(c)

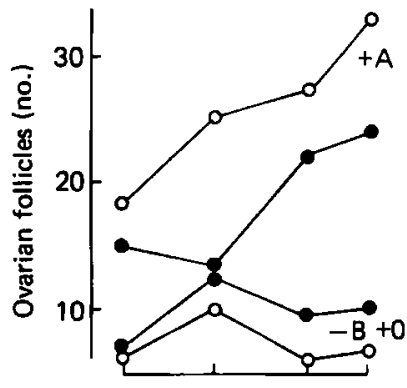

$(f)$

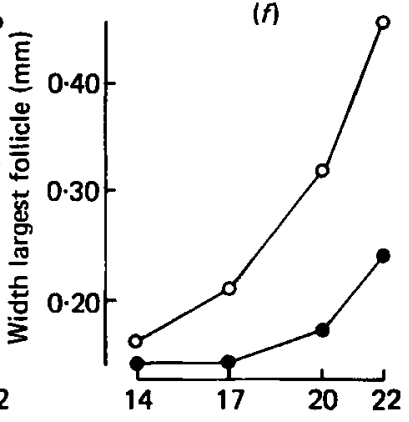

Fig. I. Effects of neonatal undernutrition on (a) body-weight $(\mathrm{g})$, $(b)$ follicle-stimulating hormone (FSH; $\mathrm{ng} / \mathrm{ml}$ National Institutes of Arthritis, Metabolism \& Digestive Diseases - rat - FSH Reference Preparation no. I) and ( $c-f)$ ovarian and uterine development ( $c$, ovarian follicles (no.); $d$, uterus weight $(\mathrm{mg})$; $e$, ovarian width $(\mathrm{mm}) ; f$, width largest follicle $(\mathrm{mm})$ ). All values are means. , Undernourished rats; $O$, control rats; $+\mathbf{A}$, antral follicles; $-\mathbf{A}+\mathbf{O}$, preantral follicles with visible oocyte.

However, undernutrition may cause primarily a prolonged persistence of relatively high blood levels of the oestrogen-binding protein (EBP; alpha-foetoprotein, AFP), thereby restraining the FSH-inhibiting influence of plasma oestradiol of which only a small proportion would be unbound. This would seem possible in view of the known effect of administration of AFP (Puig-Duran et al. 1977) and of immature (EBP-rich) oestradiol-free serum (Puig-Duran et al. 1979) to 2I-d-old female rats; both of these treatments resulted in an increase in serum FSH. Under such circumstances (including undernutrition) the delay in ovarian development could be due to the reduced effectiveness of intra-ovarian oestrogen levels for it has been demonstrated that restraining endogenous oestrogen activity with anti-oestradiol serum results in delayed ovarian development (Reiter et al. 1972). In the normal rat hepatic AFP production after birth continues only briefly (Gitlin, 1975) and the plasma concentration falls exponentially with a half-life of 3-4 d (Raynaud, 1973; Germain et al. 1978). Further experiments are needed to test the hypotheses that plasma AFP levels remain high for a longer period of time during neonatal undernutrition and that such may happen through either continued production or lengthening of the half-life of AFP. It remains uncertain through which mechanism(s) undernutrition brings about delayed onset of puberty.

The investigation was supported by the Foundation for Medical Research FUNGO which is subsidized by the Netherlands Organization for the Advancement of Pure Research (Z.W.O.). 


\section{REFERE NCES}

Germain, B. J., Campbell, P. S. \& Anderson, J. N. (1978). Endocrinology ro3, 1401.

Gitlin, D. (1975). Ann. N.Y. Acad. Sci. 259, 7.

Kennedy, G. C. \& Mitra, J. (1963). J. Physiol. Lond. 166, 408.

Kirk, R. E. (1968). Experimental design: Procedures for the Behavioral Sciences. Belmont, California:

Brooks Cole.

Kragt, C. L. \& Dahlgren, J. (1972). Neuroendocrinology 9, 30.

Lynch, A. (1976). Devl. Psychobiol. 9, 39.

Price, D. (1947). Anat. Rec. 97, 519.

Puig-Duran, E., Greenstein, B. D. \& MacKinnon, P. C. B. (1977). J. Endocr. 75, 52P.

Puig-Duran, E., Greenstein, B. D. \& MacKinnon, P. C. B. (1979). J. Reprod. Fert. 56, 707.

Raynaud, J.-P. (1973). Steroids 2r, 249.

Reiter, E. O., Goldenberg, R. L., Vaitukaitis, J. L. \& Ross, G. T. (1972). Endocrinology 9I, 1537.

Sheikholislam, B. M. \& Stempfel, R. S. (1972). Pediatrics, Springfield, 49, 362.

Uilenbroek, J. Th. J. \& Arendsen de Wolff-Exalto, E. (1979). Biol. Reprod. 20, 384.

Welschen, R., Osman, P., Dullaart, J., de Greef, W. J., Uilenbroek, J. Th. J. \& de Jong, F. H. (1975). J. Endocr. 64, 37. 